\title{
BDA Indemnity team growing with expert talent
}

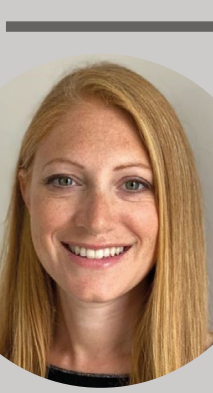

The BDA has welcomed two more experts into its dento-legal team. Clare Lawrence and Shreeti Patel join BDA Indemnity to hold members' hands through complaints and investigations.

Clare has 20 years of experience as a dentist, working in both primary and secondary care. Having worked in the dento-legal field for the last 6 years, she has continued her interest in the law and recently became a member of the Faculty of Forensic and Legal Medicine, going on to complete the diploma in forensic medical science. Clare is committed to pursuing proper and fair outcomes for her dental colleagues in all manner of dental complaints, claims, regulatory and disciplinary processes and advice cases.

Shreeti completed her Master's in Medical law and Ethics in 2018 where she focused her dissertation on consent and regulation of endodontic treatment. Since completing her first Master's in Endodontics at Guys in 1999, Shreeti practised in Oxfordshire where she was a principal dentist and provided endodontic services at two other practices in Berkshire.

With her legal and clinical expertise, Shreeti will be able assist members with complex endodontic medico legal issues amongst other complaints, claims and regulatory cases.

Len D'Cruz, who heads BDA Indemnity said: 'We are really pleased to welcome Clare and Shreeti to our team. They come

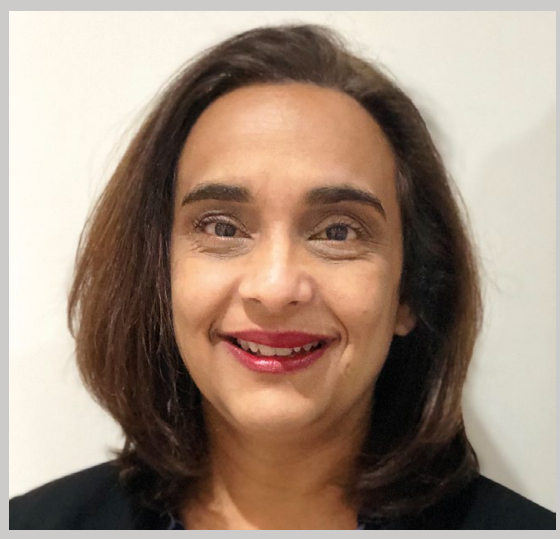

with a wealth of experience, helping us provide a high-quality dentist-to-dentist service on the phone, helping respond to complaints, providing advice as well as supporting members with any claims or GDC investigations.'

\section{HMRC announcement re associates' tax status}

The employment status of dental associates has been discussed many times in recent years. Up until now, associates had always been covered by HMRC Guidance that stated:

\section{'Associate' Dentists:}

It should be noted that there are standard forms of agreement for 'associate' dentists which have been approved by the British Dental Association (BDA) and the Dental Practitioners Association (DPA). These agreements relate to dentists practising as associates in premises run by another dentist. Where these agreements are used and the terms are followed, the income of the associate dentist is assessable under trading income rules and not as employment income. In these circumstances the dentist is liable for Class 2/4 NICs and not Class 1 NICs.

The NHS General Dental Services Contract, which came into force from 1 April 2006, provides for less fluctuation in associate dentist's income. However, providing the associate dentist continues to be responsible for paying their share of laboratory fees etc for work relating to their patients and other terms of the standard agreement are followed, the above guidance will still apply'

\section{HMRC has now} announced that this guidance for associate dentists will be withdrawn with effect from 6 April 2023 and after this date the status of new and ongoing associate dentist engagements should be considered in line with ESM0500 and CEST.

This now means

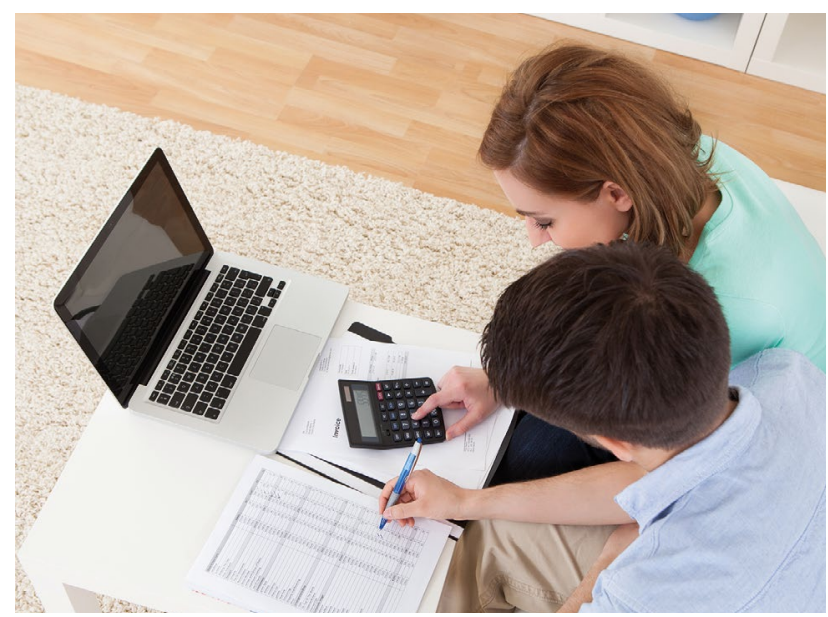
that from April

2023, all Associates' tax status should be considered on a case-by-case basis depending on the circumstances of each individual dental associate.

NASDAL Media Officer and Head of Dental Business Unit at UNW Alan Suggett said: 'Despite the withdrawal of HMRC guidance, the consensus of NASDAL accountants is that there will be no change to the self-employed status for the majority of associates.

'Associates and practice owners are advised to go through the online HMRC CEST test carefully and honestly. The result for the majority of dental associates is likely to be that they should be considered as being self-employed for tax purposes. 'However, there could be concern for those Associates whose working arrangements are subject to a higher degree of control than normal'.

NASDAL's advice to all associates and particularly new associates, is to undertake the CEST test, which is anonymous, and then retain a hard copy of the conclusions arrived at. You can access the online HMRC CEST test at www.gov.uk/guidance/ check-employment-status-for-tax. 